\title{
Differences in hip fracture care in Europe: a systematic review of recent annual reports of hip fracture registries
}

\author{
Maic Werner $^{1}$ (D) $\cdot$ Christian Macke $^{1} \cdot$ Manfred Gogol $^{1} \cdot$ Christian Krettek $^{1} \cdot$ Emmanouil Liodakis $^{1}$
}

Received: 7 July 2021 / Accepted: 26 September 2021 / Published online: 8 October 2021

(c) The Author(s) 2021

\begin{abstract}
Purpose Hip fractures are of growing interest due to their increasing number, subsequent functional decline and high institutionalization rate of patients, mortality, and costs. Several process measurements are essential for hip fracture care. To compare and improve these, hip fracture registries in Europe became popular. This systematic review aims to describe the differences between hip fracture registries in Europe as well as the differences in hip fracture treatment between countries. Methods A systematic search using the keywords "hip fracture" AND "national" AND "database OR audit OR registry OR register" was performed in PubMed, Embase and Cochrane Library according to PRISMA guidelines till 3rd December 2020. Recent annual reports of identified hip fracture registries in Europe were additionally identified in June 2021. Comparisons of most common case-mix, process and outcome measurements were performed.

Results 11 registries in Europe were identified. Differences were observed regarding inclusion criteria of the different registries. Comparison of the different registries was difficult due to differences in the way to report measurements. While mortality rates differed substantially between countries, most of the process measurements met recommendations according to recent guidelines.

Conclusion Hip fracture registries were a valid tool to compare hospitals within one country. However, a comparison between registries of different countries should have also been easily possible. For this, the registries need to make their data easily accessible and further unify their way of measuring and reporting.
\end{abstract}

Keywords Hip fracture $\cdot$ Registry $\cdot$ Audit $\cdot$ Systematic review

$\begin{array}{ll}\text { Abbreviations } \\ \text { AMTS } & \begin{array}{l}\text { American Society of Anesthesiologists risk } \\ \text { classification }\end{array} \\ \text { ASA-Score } & \begin{array}{l}\text { Abbreviated Mental Test Score } \\ \text { Cumulated Ambulation Score }\end{array} \\ \text { CAS } & \text { Charlson Comorbidity Index } \\ \text { CCI } & \text { Dynamic hip screw } \\ \text { DHS } & \text { Fragility Fracture Network } \\ \text { FFN } & \text { Great Britain Pound } \\ \text { GBP } & \text { Intramedullary nail } \\ \text { IM-Nail } & \text { National Hip Fracture Database } \\ \text { NHFD } & \text { Short Portable Mental Status Questionnaire } \\ \text { SPMSQ } & \end{array}$

This work was performed at the Hannover Medical School, Hannover, Germany.

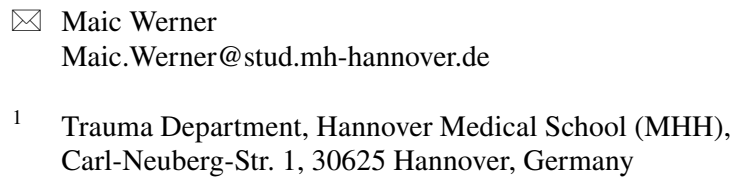

\section{Background}

Hip fractures are a major health care problem in developed countries. Approximately, 600,000 hip fractures occurred in Europe in 2010 [1]. Calculations expect an ongoing increase with 4.5 million hip fractures worldwide occurring in 2050 [2]. Mostly older patients experience a hip fracture and 25\% of them die within 1 year $[3,4]$.

While the policies in most European countries are partially connected by their membership in the European Union, most aspects of health policies are governed by each country [5]. This results in different health care systems [6]. Disparities in process and outcome measures for hip fracture patients between European countries have been shown [7, 8]. Not only the delivered health care varied, but also the incidence of hip fractures. The highest rate of hip fractures worldwide was occurring in northern Europe, while the lowest rates in Europe were reported in Switzerland and France [9]. 
Treating hip fracture patients is a challenging task as the high mortality rates are showing. Some process measurements are essential for hip fracture treatment. It could be shown that patients' mortality rates could be reduced by performing surgery within $24 \mathrm{~h}$ of admission to the hospital [10]. Treating these patients together with colleagues in geriatric medicine-so-called orthogeriatric co-management or geriatric trauma unit-showed an additional reduction in mortality rates [11]. Treating osteoporosis reduced the mortality after hip fracture and a falls risk assessment reduced the risk of falling in older adults $[12,13]$.

To improve the management and outcome of these patients continuously, it is necessary that process and outcome parameters are collected and compared. In 1988, the first hip fracture registry started in Sweden, followed by Scotland in 1993 [14, 15]. Since then, many other hip fracture registries started to collect data, most of them in Europe [16]. However, the variables, which the registries collected, differed between the registries in Europe. To improve the comparability of outcome and process measures in hip fracture registries, the Fragility Fracture Network (FFN) prepared a minimum common dataset in 2013 that is already used in many of them [17].

The purpose of this systematic literature review is to determine the differences in hip fracture care within Europe by comparing the current literature and latest annual reports. Additionally, the differences in the methods of the different registries and their strengths and weaknesses will be discussed.

\section{Materials and methods}

\section{Search strategy}

A systematic search according to PRISMA guidelines using the search terms and Boolean Operators "hip fracture AND national AND (database OR audit OR registry OR register)" in PubMed, Embase and Cochrane Library was performed as of the earliest records till 3rd December 2020 by the first author. The search in PubMed and Embase was limited to the languages English and German. Abstracts and titles were screened for the clear referring to a hip fracture database/ audit/registry/register on national basis in European countries. Registries without the clear sole focus on hip fractures were excluded. Analyses of hospital discharge records, national patient databases, administrative claims databases or health insurance data were not considered. Only online available full-text articles with an available abstract were considered.

With the above-described search, the hip fracture registries in Europe that were included in the quantitative comparison were identified. An online web search for the annual reports of the identified registries was performed. No language restriction for the annual reports was applied. Annual reports not in English or German were translated using a web-based translator. Moreover, the websites of the registries were searched for additional information on methods and the registries were contacted if information on methods were missing.

This review was not registered. Ethical approval was given as a waiver by the ethics committee of Hannover Medical School (Nr. 9135_BO_K_2020).

\section{Quantitative comparison of registries}

For the comparison of hip fracture registries the case-mix, process and outcome parameters reported in equal ways in the different annual reports and most recent papers were identified. Categorical variables were pooled into the mostly used categories. Due to information governance, it was not possible to easily access the raw data of the registries. If the used annual reports or paper did not publish these measurements, the papers of Ojeda-Thies et al. and Johansen et al. who used previous annual reports in their analysis, were mainly used $[16,18]$. The data are presented in absolute numbers and percentages, as given in the annual reports. No statistical test for comparison was performed.

\section{Results}

\section{Study selection}

With this search strategy, 3980 records in Embase, 1400 in PubMed and 478 in Cochrane Library till 3rd December 2020 were identified. After removal of duplicates, 4786 records were left. 349 records were assessed as a full-text after discarding the rest based on the abstract and the title. 176 records were excluded further at this step. Mainly because the abstracts had no full-text available as they were often conference abstracts. One record was excluded for not mentioning a hip fracture registry in the full-text, 6 were excluded because the registry mentioned was not up-to-date and a more up-to-date registry for the same country was found, 3 were the abstracts of a clinical trial registration at clinicaltrials.gov and for one article no full-text could be obtained after a thorough search. 173 full-texts were accessed and searched for the in the abstract mentioned hip fracture database/audit/registry/ register and the corresponding country. Eleven different countries with a hip fracture database/audit/registry/ register were detected. With this web-based search nine annual reports were found: Sweden [14], Scotland [19], Denmark [20], Norway [21], England/Wales/Northern Ireland (National Hip Fracture Database-NHFD) [22], 
Ireland [23], Germany [24], Netherlands [25] and Spain [26]. For Finland, the data were available in a web-based dashboard [27]. For the NHFD, additional information was also obtained using their dashboard [22]. Italy had no annual report available, only two research papers [28, 29]. The annual reports included for the countries reported in the most cases on the year 2019, but for Finland, the data were presented for the year 2018 and for Italy from 01.02.2016 to 31.07.2018. For some parts of the methods and quantitative analysis, additional paper were used $[16,18,30-32]$. The flowchart of the literature search is displayed in Fig. 1.

\section{Characteristics of registries}

Eleven hip fracture registries in Europe with recent data were identified: four in the north of Europe, two in the Mediterranean area and the rest in central Europe. The first registry started 1988 in Sweden and the latest 2017 in Spain. The registries varied in their inclusion criteria. Most hip fracture registries were including patients with a minimal age of 50 or more. However, the Netherlands included patients as soon as they become adults and Norway tried to include all hip fracture patients, regardless of age. Consent was not necessary in some registries. The inclusion of pathological and periprosthetic fractures was performed differently and not all registries stated this exactly in their inclusion or exclusion

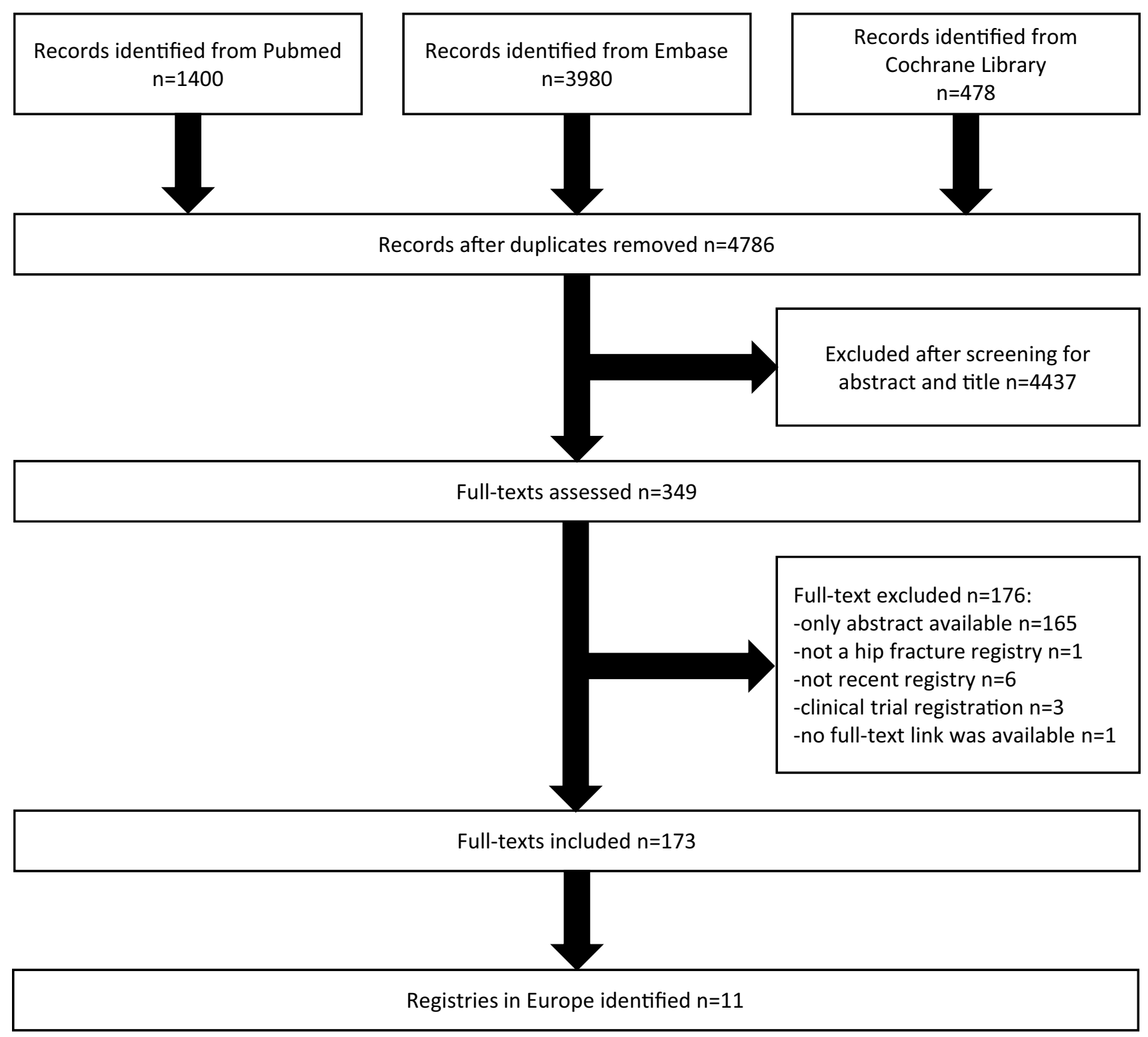

Fig. 1 Flow diagram of record assessment 
criteria, e.g., Germany was the only registry clearly stating in their methodology that they include periprosthetic fractures. Conservative treatment of hip fractures was an exclusion criterion in some registries. In Finland, being a resident of a nursing home was also an exclusion criteria [31]. The follow-up period varied between 1 and 36 months in the different registries. Most importantly, not all registries covered all fractures in their country and hereby only represented a part of the whole patient collective, who were treated in special selected hospitals. The role model for inclusion of most cases was the NHFD with 67,302 cases in 2019 from 174 hospitals in England, Wales and Northern Ireland. In Italy, only 14 hospitals participated and these reported the cases on a voluntary basis. The hospitals that reported data to the German hip fracture registry had to meet special process criteria before they were included in the registry. Not only the inclusion criteria varied extremely between the different registries but also the accessibility of the data. Not all registries published annual reports in English language, which made the correct understanding difficult.

The different inclusion criteria, used from the registries across Europe, were a possible problem, because they could have resulted in a selection bias. Moreover, the interpretations of the data in the annual reports of the registries should be read thoughtfully since the annual reports were created by persons affiliated to the registries.

\section{Collected variables}

To compare hip fracture care between the different countries uniform measurements needed to be used. Many registries aligned their data collection on the minimum common dataset of the FFN [17]. However, some registries differed considerable from this dataset. For example, Norway's reported data focused more on surgical procedures than on other process or outcome measurements. The Finnish database was retrospectively based on other national databases, which limited the data from this registry. Additionally, the registries presented not all their data in the publicly available annual reports. The way to present these data differed between the registries. Comparison of follow-up data was due to different follow-up timeframes difficult.

\section{Proportion of registered cases}

To interpret the results correctly, data regarding the registered cases was essential. The registries that presented numbers on proportion of the registered cases ranged between 78.9\% in Sweden and 100\% in Denmark. Danish hospitals were obliged by law to report cases [30]. Finland included all data from the hospital discharge records, and therefore, should have high percentages of registered cases within their inclusion criteria. For Germany, Italy and Spain, no data regarding the proportion of the registered vs. total national cases were reported. In these countries not all hospitals participated and therefore a high percentage of cases in the country were not included (Table 1).

\section{Basic patients' variables}

The average patient was older than 80 years and in over $66 \%$ female. Prior to fracture, most patients lived at home ranging from $60 \%$ in the Netherlands to about $90 \%$ in Italy. 33-50\% of the patients could walk without an aid outdoors before fracture. Sweden and Spain reported the mobility in different categories as the other registries and were, therefore, not included in the table and Denmark used the Cumulated Ambulation Score (CAS). The average patient had many comorbidities reflected by an ASA-Score (American Society of Anesthesiologists risk classification) of $\geq 3$ in 58\%-74.5\% patients. Denmark used for the comorbidities instead of the ASA-Score the Charlson Comorbidity Index (CCI). Also, between 17 and 43.9 percent of the patients had already cognitive problems (Table 2).

\section{Process variables}

The operative treatment varied with the predominant fracture type between a hemiarthroplasty and a femoral nail. A dynamic hip screw (DHS) was used in Germany, Spain and Italy very rarely in comparison to other countries. Most of the prostheses were cemented. The anaesthetic procedure varied strongly between the different countries, too. While in Germany spinal anaesthesia was not common, this was the mostly used technique in Sweden and several other countries (Table 3).

Only some reports analysed the time from the emergency room until transfer to a ward or operation room. While in Ireland only $25 \%$ of the patients were admitted to a ward in under $4 \mathrm{~h}$, this was the case for $81 \%$ in Scotland. The longest time frame to surgery was reported from Spain and Italy with a mean of $64.6 \mathrm{~h}$ in Spain and $54 \mathrm{~h}$ in Italy. In contrast to these long periods till fracture treatment Sweden, Denmark, Germany and the Netherlands showed the highest rates of surgical repair within $24 \mathrm{~h}$ with about two third of the patients. The lowest median was reported from Germany with $17.8 \mathrm{~h}$. Mobilization rates on the first day after surgery varied between $68 \%$ in Scotland and $82 \%$ in Ireland. Joint care with geriatricians was lowest in Netherlands with $74 \%$ and highest in the NHFD with $91 \%$. Falls assessment was performed on $83-96.6 \%$ of the patients in the reporting registries and bone health assessment was assessed in over $90 \%$ of the patients. Falls assessment included in the most registries a review of previous falls, cause of index fall and further risk factors for falling and injury. Bone health assessment was defined in the registries as getting medication for osteoporosis, being assessed for eligibility of 


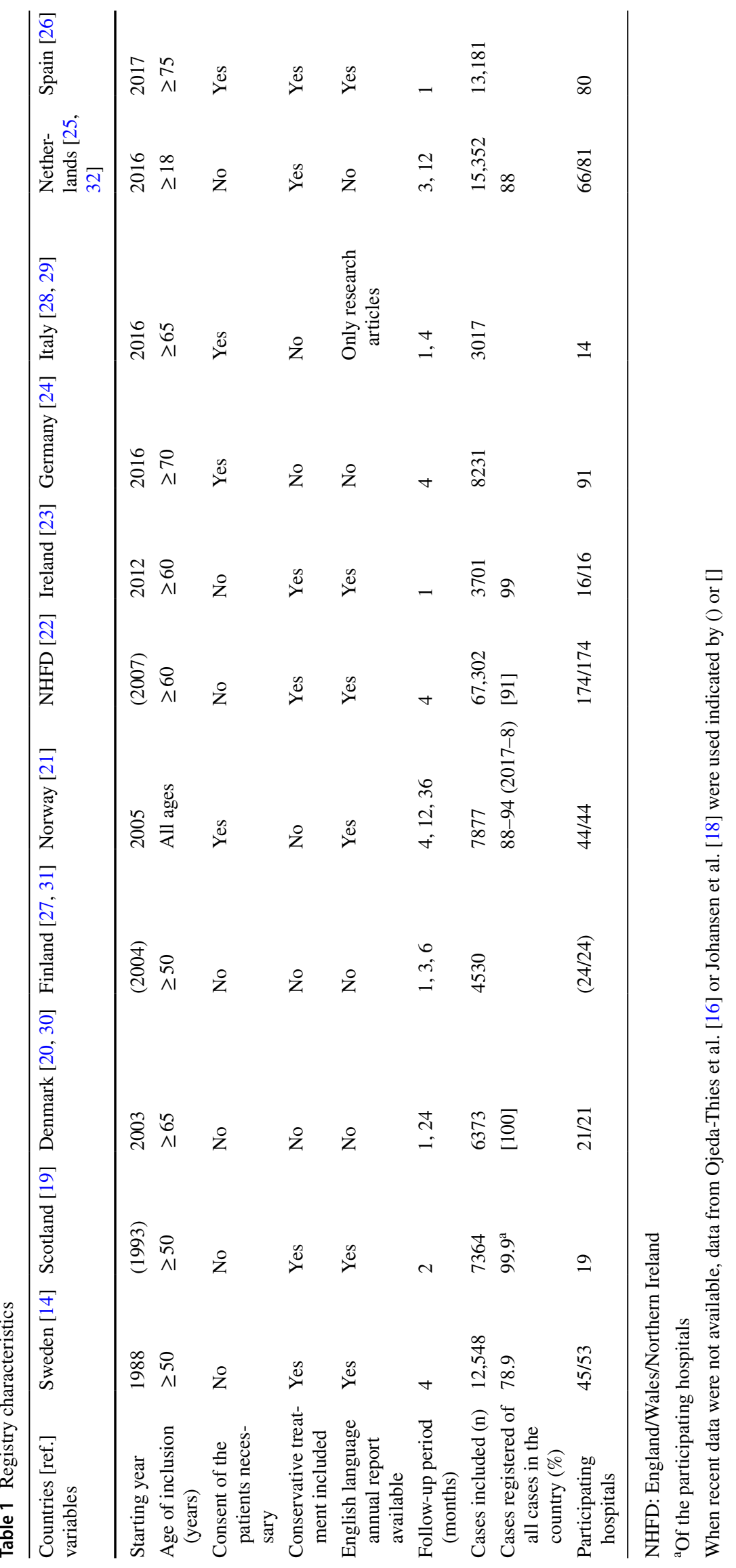




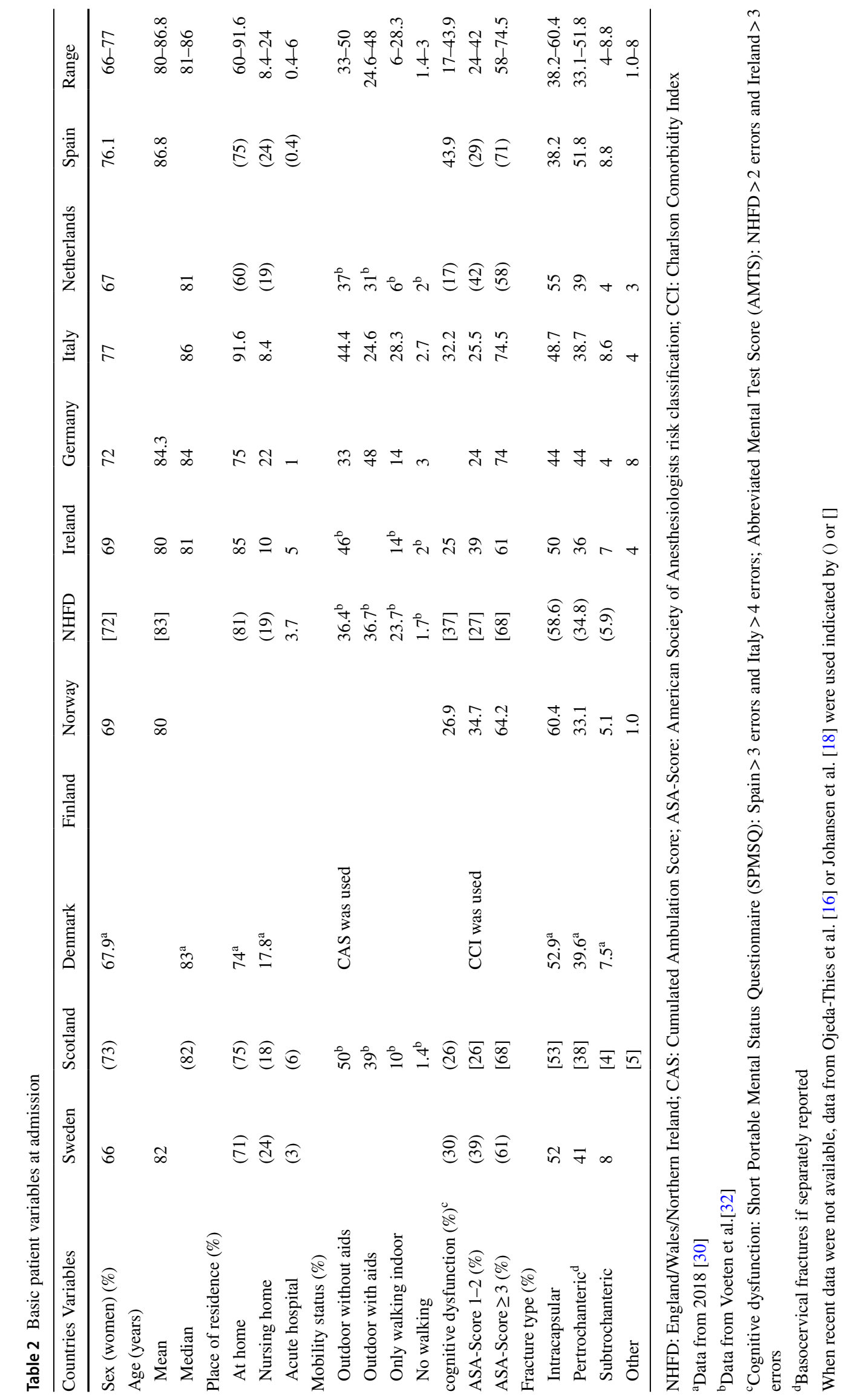


Table 3 Operative and anaesthetic treatment

\begin{tabular}{|c|c|c|c|c|c|c|c|c|c|c|c|c|}
\hline Countries Variables & Sweden & Scotland & Denmark & Finland & Norway & NHFD & Ireland & Germany & Italy & Netherlands & Spain & Range \\
\hline \multicolumn{13}{|l|}{ Surgical procedure (\%) } \\
\hline Conservative & (1) & & & & & (2.2) & (5) & & & 3 & 2.4 & $1-5$ \\
\hline Cannulated screws & (15) & (2) & {$[10]$} & & 11.4 & (3) & $2^{\mathrm{a}}$ & (2) & 4.2 & 5 & $2.2^{\mathrm{a}}$ & $2-15$ \\
\hline DHS & $(20)$ & (34) & {$[22]$} & & 15.3 & $(32)$ & $15^{\mathrm{a}}$ & (3) & 4.3 & 13 & $1.4^{\mathrm{a}}$ & $1.4-34$ \\
\hline IM-Nail & (27) & (10) & {$[31]$} & & 23.4 & (12) & $28^{\mathrm{a}}$ & $(50)$ & 49.9 & 39 & $60.5^{\mathrm{a}}$ & $10-60.5$ \\
\hline Hemiarthroplasty & (25) & $(48)$ & {$[25]$} & & 41.7 & (43) & $47^{\mathrm{a}}$ & (34) & 24.2 & 33 & $33.2^{\mathrm{a}}$ & $24.2-48$ \\
\hline Total hip replacement & (10) & (6) & {$[10]$} & & 7.8 & (8) & $4^{\mathrm{a}}$ & (6) & 15.4 & 7 & $2.7^{\mathrm{a}}$ & $2.7-15.4$ \\
\hline Cemented prosthesis & [97] & $94.7^{\mathrm{b}}$ & & & $93.1^{\mathrm{b}}$ & 92.3 & 76 & & & & & $76-97$ \\
\hline \multicolumn{13}{|c|}{ Anaesthetic technique $(\%)^{\mathrm{c}}$} \\
\hline Spinal & {$[95]$} & {$[50]$} & & & 79.6 & 45.2 & 77 & 6 & 76.7 & 63 & 93.1 & $6-95$ \\
\hline General & {$[5]$} & [44] & & & 16.0 & 56.5 & 24 & 94 & 20.2 & 43 & 6.3 & $5-94$ \\
\hline
\end{tabular}

NHFD: England/Wales/Northern Ireland; DHS: dynamic hip screw; IM-Nail: intramedullary nail

${ }^{a}$ Of all operations (excluding conservative treatment)

${ }^{\mathrm{b}} \mathrm{Of}$ the hemiarthroplasties

${ }^{\mathrm{c}}$ More than one technique possible per patient

When recent data were not available, data from Ojeda-Thies et al. [16] or Johansen et al. [18] were used indicated by () or []

medication for osteoporosis or initiated outpatient diagnostics. Different rates of bone health assessment resulted in different rates of medical treatment of osteoporosis after hip fracture ranging from $10 \%$ in Germany to $71 \%$ in Ireland (Table 4).

\section{Outcome variables}

The registries reported extreme different lengths of hospital stay from 4.2 days in Finland to 19.5 days in Ireland. The two non-surgical complications presented by some registries were pressure sores and delirium. The percentage varied between 3 and $4.8 \%$ in the reporting countries for pressure sores and 25\%-30\% for delirium. Most patients were discharged in a rehabilitation facility or directly home. The mortality rates in the hospital episode differed considerable between the countries with $1.5 \%$ in Italy and $6 \%$ in Germany.

Follow-up results were reported heterogeneously. Readmissions were reported only for orthopaedic reasons or for all causes and the time frames varied between 14 and 120 days. So, comparisons were not applicable. The same problem arose for re-operation rates. $2 \%$ were re-operated within 30 days and $3 \%-4 \%$ within 120 days. After 2 years, between 3 and $12 \%$ were re-operated depending on the fracture type and surgical procedure. The mortality rates after hip fracture varied between 5.5\% and 9.5\% after 1 month (Table 5).

\section{Discussion}

Our systematic review revealed 11 hip fracture registries within Europe. Different inclusion criteria (e.g. age) were detected. Huge variations between the registries were visible with regard to surgical or anaesthetic method. Time to surgery as a key performance measurement varied considerable. Mortality as the most important outcome measurement ranged between $5.5 \%$ and $9.5 \%$ at 30 days. Several aspects needed to be kept in mind when comparing the different databases.

Errors in different hip fracture databases are known [33-36]. In most cases, the data for the registries were reported by the regular staff and had to be done additionally to their work. In order for a high participation rate, the staff should have time for collecting registry data [37]. Data errors could be reduced using electronic health records or further using data managers $[33,35]$.

Not all countries included all cases and all hospitals. In Germany about 169.000 hip fractures were counted in 2019 and the German registry reported only 8231 ( 5\%) cases [38]. Therefore, a negative or positive selection bias was possible. The same applied for Italy and Spain.

Moreover, measurements, the way to collect them and also the way to present them, varied between different registries. Not always were all collected measurements presented in the latest annual report. As a result, the comparison between the countries was limited.

The basic patient variables varied depending on the different inclusion criteria, e.g., the inclusion of younger hip fracture patients in the registries could have resulted in lower ASA-Scores [39]. While men are younger when they suffer from a hip fracture, a bigger proportion of male patients could have been expected [3]. Differences in the diagnosis of cognitive impairment might have also been attributed to different inclusion ages. Two tests were mostly used for cognitive dysfunction: the Pfeiffer Short Portable Mental Status 


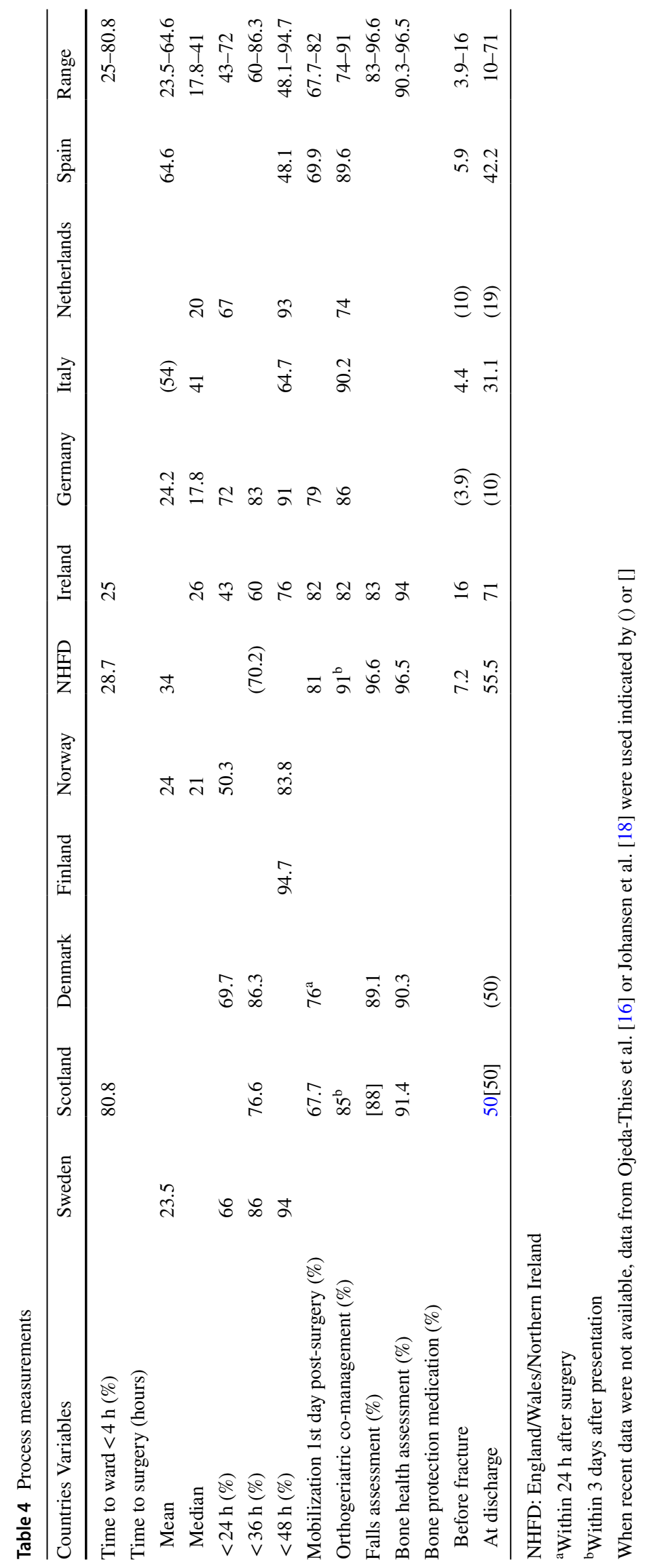




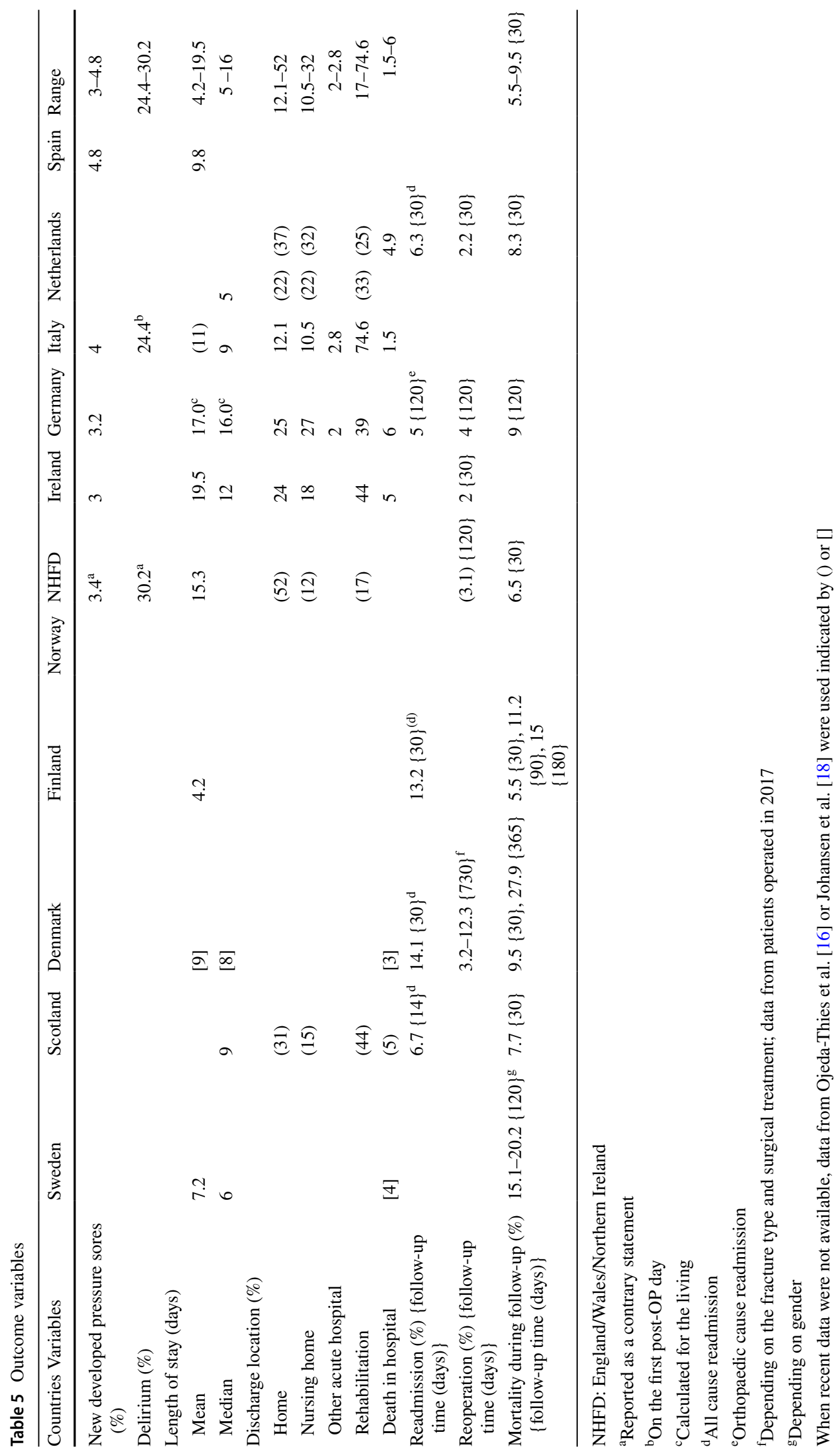


Questionnaire (SPMSQ) and the Abbreviated Mental Test Score (AMTS). In addition to different questionnaires used in the registries, the cut-offs varied additionally and comparison was difficult. The walking ability prior to fracture was reported in the registries with different categories or scores. Only Denmark used the Cumulated Ambulation Score (CAS). To reach more comparability Voeten et al. recommended to use common categories like the Fracture Mobility Score that was already used in many registries [40]. Scores like the Parker Mobility Score would need more questions. The aim for registry questionnaires should be simplicity to achieve a good data completeness [40]. Differences in fracture type might have been explained in part with more intertrochanteric fractures occurring in older patients as observed in Spain and Germany [41, 42]. Spain and Germany had the oldest mean age of all registries and also the highest rate of pertrochanteric fractures. However, Italy with a comparable median age had predominantly intracapsular fractures.

Surgical treatment varied between the different countries. This might have been partly explained by different frequencies of fracture types and subtypes. However, there is still ongoing discussion when to use which implant for intertrochanteric or intracapsular fractures [43-46]. Different guidelines in the countries and surgical tradition might have also explained different surgical procedures. Data from the Norwegian Hip Fracture Registry recommended using cemented hemiarthroplasties for femoral neck fracture, because of lower reoperation rates and no differences in 1-year mortality in comparison to uncemented hemiarthroplasty [47]. However, a higher mortality rate within $48 \mathrm{~h}$ was found in a recent meta-analysis for cemented hemiarthroplasties, but also not after one year [48].

The same applied for procedures in anaesthesia. While most countries favoured regional anaesthetic techniques over general anaesthesia, yet there seems to be no clear evidence favouring one of both techniques [49-51]. However, the results of a randomised controlled multi-centre study in Germany, focussing on a geriatric population, may show the benefit of spinal or general anaesthesia [52].

The Blue Book, published 2007 by the British Orthopaedic Association and British Geriatric Society, focused on 6 process variables that needed to be improved for good hip fracture care: time to ward $<4 \mathrm{~h}$, time to surgery $<48 \mathrm{~h}$, pressure sore prevention, orthogeriatric co-management, bone health and falls assessment [53]. These variables were at least partly measured in the most registries and reported in their annual reports.

The Blue Book demanded for a surgical repair of hip fractures within $48 \mathrm{~h}$ [53]. However, newer analysis came to the conclusion that a time to surgery within $24 \mathrm{~h}$ could be more beneficial for patients [10]. Many countries were able to operate about $90 \%$ within $48 \mathrm{~h}$. The highest rate of operations within $24 \mathrm{~h}$ was seen in Germany with $72 \%$. In Spain and Italy, these numbers were worse and improvement was needed. Spain was already in the process of reducing their time to surgery and reduced the time to surgery about $10 \mathrm{~h}$ in comparison with the annual report of 2017 [16].

However, despite this evidence, some authors believe that the benefits of a reduced time to surgery with regard to mortality are explained by a selection bias [54, 55]. A recent study using data of the German registry found also no evidence for a reduction in mortality [56]. This study is one of many examples for important research questions that were more clarified by the use of data from such big databases.

Orthogeriatric co-management for older hip fracture patients has been proven effective in the last years [11]. The best way to perform this co-management is not yet examined according to recent meta-analyses [57, 58]. The frequency of orthogeriatric co-management should be higher than one visit per week, since this model did not resulted in improved mortality or complication rates [59]. Given the positive effect described above, it should be the aim that every geriatric hip fracture patient is managed collaboratively with a geriatrician. In Germany, orthogeriatric co-management was mandatory for the registration in the hip fracture registry. Therefore, the number in whole Germany could be lower. In countries with low inclusion ages, the percentage of patients without the need of orthogeriatric management could influence this comparison.

It was pleasing that nearly all registries that reported on bone health assessment and falls prevention performed them very frequent to prevent further fractures. Germany did not present frequencies on bone health assessment, but the patients with therapy of osteoporosis at discharge were extreme low. This indicated that more patients should have been assessed for bone health during the hospital stay and more patients should have been prescribed medication for osteoporosis.

The reports on outcome variables were rare. Especially delirium is a common complication after hip fracture [60]. Only two registries reported data on delirium and these rates were with about $25 \%$ much lower than reported in other studies [60]. As a conclusion, more tests on delirium should be performed with a special focus on the hypoactive form which is much harder to detect and likely underrepresented $[28,61]$.

The length of stay between the different countries varied extremely. When a rehabilitation unit was an integrated part of the hip fracture ward it was clear that the length of stay was longer. Structural differences between hospitals and countries might have also resulted in different discharge destinations.

A striking point were the reported inpatient mortality rates and mortality rates after 1 month between the registries. The lowest inpatient mortality was reported in Italy with only $1.5 \%$. Germany had the highest with $6 \%$. For 
the one month mortality the rates differed between $5.5 \%$ in Finland and 9.5\% in Denmark. Differences in mortality might have been partly explained by different inclusion criteria, e.g. age, and hereby healthier patients. This explanation did not apply to Italy with $75 \%$ showing an ASA-Score of 3 or more. Due to the fact that in Italy not all cases in the hospitals had to be reported it might have been that patients who died were less likely included. The low 30-day mortality in Finland was most likely explained by the exclusion of institutionalised patients since institutionalisation is one risk factor for mortality [4]. The high risk of dying in Germany might have been partly explained by their inclusion of periprosthetic fractures, as they are of increased risk of dying [62] Other follow-up measurements were hard to compare due to much variation in collected data and their follow-up period.

Hip fracture registries require funding due to high costs. In the NHFD about 37 Great Britain Pounds (GBP) were needed for central and local data management [63]. These costs were very low in contrast to the hospital costs in the first year after fracture with about 14.000 GBP per hip fracture in the UK [64]. To justify these costs, the effect on improved care must be clear. However, the effect of hip fracture registries on performance improvement is difficult to measure. It is hard to determine which effects can be addressed to continuous performance surveillance and which are rather explained by other improvements in hip fracture care, such as hip fracture care pathways or special dedicated timeslots in the operation theatre. Moreover, the data of a registry seem to be biased for measuring itself improvement. Therefore, Neuburger et al. compared the proportion of patients receiving early surgery and 30-day mortality for all eligible patients in England 4 years prior to the implementation of the NHFD and 4 years after with external data [65]. They found a significant improvement in both outcomes after NHFD implementation. Other reports from Norway or Denmark showed also a performance improvement in some of the measured parameters over the years of implementation [30, 66] Another question may be how often audits and data collection are necessary for continuous improvements. Ferguson et al. found that in Scotland, after stopping yearly audits for 5 years, the improved quality of care declined again [15]. They recommended regular audits for maintaining the achieved improvements.

Quality improvement is not only achieved by comparing process variables within one country, but also by accompanied research. Edwards et al. showed that small improvements in hip fracture care between two groups need high numbers of included patients to be significant [67]. National registries included a large amount of patient information. With big data studies, research questions could be answered more certain and bias would be less of a problem [68].

Hip fracture registries were a valid tool for comparison of important process and outcome markers between hospitals in one country. Possibilities for improvement could be easily identified. However, a comparison between different hip fracture registries was difficult. Not only differences were observed with regard to which data were collected, but also how to present them. Initiatives as the FFN with a common dataset could further improve the comparability between different hip fracture registries. In the era of globalization, it should have been a standard that English language annual reports were online available so that not only hospitals in one country could compare their performance but also whole countries between each other. Sweden provided an English version after contacting and Spain will provide an English version later in the year.

Our study has several limitations. The biggest limitation is that we could not get access to the raw data and analysis was limited to published data. Comparison of data was complicated as described above. Especially the different inclusion criteria, used by the different registries, resulted in a possible selection bias. This limited the comparability of different outcome parameters considerable, as already discussed. With regard to eliminating possible bias, highquality randomised controlled trials are still superior. Furthermore, registry data could contain errors, as mentioned earlier. Additionally, the institution of the authors of this review is part of the German registry. This should be kept in mind while interpreting the authors' conclusions.

Besides data limitation, this study has important strengths. To the best of our knowledge, this is the first study that focused on the comparison of only European hip fracture registries. With this concentration on the European registries, a more detailed comparison was possible. Moreover, recent available data were used in this study and together with older data, most aspects of hip fracture care could be compared adequately.

\section{Conclusion}

Hip fracture care varied between the European countries. While hip fracture registries were a good tool to compare hospitals within one country, comparison between different countries and registries was difficult and, therefore, with limitations. Most countries were on the right track for fulfilling the process parameters mentioned in the Blue Book and recent research demanded. Especially, the time to surgery needed to be improved in some countries. The registries should try to make their collected and presented 
data further uniform, so that international comparisons become more feasible.

Author contributions All authors made substantial intellectual contributions to this review. MW, CM, MG, CK and EL designed the study. MW and EL developed the search strategy and performed the data analysis. The literature review was conducted by MW. The initial draft of the manuscript was written by MW and EL. CM, MG and CK reviewed the manuscript and provided helpful advice. All authors were involved in writing the manuscript and approved the final manuscript.

Funding Open Access funding enabled and organized by Projekt DEAL. M.W. was a participant of the KlinStrucMed program at Hannover Medical School funded by the "Else Kröner-Fresenius Stiftung" that enabled medical students to focus on their thesis for one year.

Data availability All data analysed in this review are included in this manuscript.

Code availability Not applicable.

\section{Declarations}

Conflict of interest All authors declare that they have no competing interests.

Ethics approval Ethics approval was obtained by the ethics committee of Hannover Medical School (Nr. 9135_BO_K_2020). The procedures used in this study adhere to the tenets of the Declaration of Helsinki.

Consent to participate Not applicable.

Consent for publication Not applicable.

Open Access This article is licensed under a Creative Commons Attribution 4.0 International License, which permits use, sharing, adaptation, distribution and reproduction in any medium or format, as long as you give appropriate credit to the original author(s) and the source, provide a link to the Creative Commons licence, and indicate if changes were made. The images or other third party material in this article are included in the article's Creative Commons licence, unless indicated otherwise in a credit line to the material. If material is not included in the article's Creative Commons licence and your intended use is not permitted by statutory regulation or exceeds the permitted use, you will need to obtain permission directly from the copyright holder. To view a copy of this licence, visit http://creativecommons.org/licenses/by/4.0/.

\section{References}

1. Hernlund E, Svedbom A, Ivergård M, Compston J, Cooper C, Stenmark J, McCloskey EV, Jönsson B, Kanis JA. Osteoporosis in the European Union: medical management, epidemiology and economic burden. A report prepared in collaboration with the international osteoporosis foundation (IOF) and the European federation of pharmaceutical industry associations (EFPIA). Arch Osteoporos. 2013;8(1):136.

2. Gullberg B, Johnell O, Kanis JA. World-wide projections for hip fracture. Osteoporos Int. 1997;7(5):407-13.
3. Sterling RS. Gender and race/ethnicity differences in hip fracture incidence, morbidity, mortality, and function. Clin Orthop Relat Res. 2011;469(7):1913-8.

4. Hu F, Jiang C, Shen J, Tang P, Wang Y. Preoperative predictors for mortality following hip fracture surgery: a systematic review and meta-analysis. Injury. 2012;43(6):676-85.

5. Cucic S. European Union health policy and its implications for national convergence. Int J Qual Health Care. 2000;12(3):217-25.

6. Gaeta M, Campanella F, Capasso L, Schifino GM, Gentile L, Banfi G, Pelissero G, Ricci C. An overview of different health indicators used in the European health systems. J Prev Med Hyg. 2017;58(2):E114-20.

7. Medin E, Goude F, Melberg HO, Tediosi F, Belicza E, Peltola $\mathrm{M}$; EuroHOPE study group. European regional differences in allcause mortality and length of stay for patients with hip fracture. Health Econ. 2015;24(2):53-64.

8. Murray CE, Fuchs A, Grünewald H, Godkin O, Südkamp NP, Konstantinidis L. Identifying disparities in the management of hip fractures within Europe: a comparison of 3 health-care systems. Geriatr Orthop Surg Rehabil. 2019;10:2151459319872941.

9. Dhanwal DK, Dennison EM, Harvey NC, Cooper C. Epidemiology of hip fracture: worldwide geographic variation. Indian J Orthop. 2011;45(1):15-22.

10. Pincus D, Ravi B, Wasserstein D, Huang A, Paterson JM, Nathens $\mathrm{AB}$, Kreder HJ, Jenkinson RJ, Wodchis WP. Association between wait time and 30-day mortality in adults undergoing hip fracture surgery. JAMA. 2017;318(20):1994-2003.

11. Rapp K, Becker C, Todd C, Rothenbacher D, Schulz C, König $\mathrm{HH}$, Liener U, Hartwig E, Büchele G. The association between orthogeriatric co-management and mortality following hip fracture. Dtsch Arztebl Int. 2020;117(4):53-9.

12. Beaupre LA, Morrish DW, Hanley DA, Maksymowych WP, Bell NR, Juby AG, Majumdar SR. Oral bisphosphonates are associated with reduced mortality after hip fracture. Osteoporos Int. 2011;22(3):983-91.

13. Chang JT, Morton SC, Rubenstein LZ, Mojica WA, Maglione M, Suttorp MJ, Roth EA, Shekelle PG. Interventions for the prevention of falls in older adults: systematic review and meta-analysis of randomised clinical trials. BMJ. 2004;328(7441):680.

14. Swedish Hip Fracture Registry Rikshöft. Annual report 2020. https://04e8d8b0-c67b-4aa0-a7e7-d272a37c2285.filesusr. com/ugd/3ac01b_7ed6560d1255425b964d6b19833f148e.pdf. (Accessed 13 Jun 2021)

15. Ferguson KB, Halai M, Winter A, Elswood T, Smith R, Hutchison JD, Holt G. National audits of hip fractures: are yearly audits required? Injury. 2016;47(2):439-43.

16. Ojeda-Thies C, Sáez-López P, Currie CT, Tarazona-Santalbina FJ, Alarcón T, Muñoz-Pascual A, Pareja T, Gómez-Campelo P, Montero-Fernández N, Mora-Fernández J, Larrainzar-Garijo R, Gil-Garay E, Etxebarría-Foronda I, Caeiro JR, Díez-Pérez A, Prieto-Alhambra D, Navarro-Castellanos L, Otero-Puime A, González-Montalvo JI; participants in the RNFC. Spanish national hip fracture registry (RNFC): analysis of its first annual report and international comparison with other established registries. Osteoporos Int. 2019;30(6):1243-54.

17. Krušič D, Brilej D, Currie C, Komadina R. Audit of geriatric hip fracture care-a Slovenian trauma center analysis. Wien Klin Wochenschr. 2016;128(Suppl 7):527-34.

18. Johansen A, Golding D, Brent L, Close J, Gjertsen JE, Holt G, Hommel A, Pedersen AB, Röck ND, Thorngren KG. Using national hip fracture registries and audit databases to develop an international perspective. Injury. 2017;48(10):2174-9.

19. The Scottish Hip Fracture Registry. Annual report 2020. https:// www.shfa.scot.nhs.uk/Reports/_docs/2020-09-15-SHFA-Report. pdf, (Accessed 12 June 2021) 
20. The Danish Hip Fracture Registry. Annual report 2019. https:// www.sundhed.dk/content/cms/62/4662_hofte_lprrapport_2019_ endelig_off.pdf. (Accessed 8 June 2021)

21. The Norway Hip Fracture Registry. Annual report 2020. http://nrlweb.ihelse.net/eng/Rapporter/Report2020_english.pdf. (Accessed 12 June 2021)

22. Royal College of Physicians The challenge of the next decade: are hip fracture services ready? A review of data from the National Hip Fracture Database (January-December 2019). London: RCP, 2021. Copyright HQIP (Healthcare Quality Improvement Partnership UK). https://www.nhfd.co.uk/files/2020ReportFiles/ NHFD_Annual_Report_2020.pdf and online dashboard 2019. Copyright Royal College of Physicians, Crown Informatics and HQIP (Healthcare Quality Improvement Partnership UK). https:// www.nhfd.co.uk/20/nhfdcharts.nsf/fmdashboard?readform $=\&$ year $=2019$. (Accessed both 11 June 2021)

23. National Office of Clinical Audit, (2020) Irish Hip Fracture Database National Report 2019. Dublin: National Office of Clinical Audit. http://s3-eu-west-1.amazonaws.com/noca-uploads/gener al/Irish_Hip_Fracture_Database_National_Report_2019_10.11. 2020.pdf, (Accessed 9 June 2021)

24. Jahresbericht 2020 AltersTrauma-Register DGU ${ }^{\circledR}$, www.alter straumaregister-dgu.de. (Accessed 8 June 2021)

25. The Dutch Hip Fracture Registry. Annual report 2019. https:// dica.nl/jaarrapportage-2019/dhfa. (Accessed 11 June 2021)

26. The Spanish Hip Fracture Registry. Annual report 2019. http:// rnfc.es/wp-content/uploads/2021/03/Informe-Anual-RNFC2019_digital-1.pdf. (Accessed 12 June 2021)

27. The Finish Hip Fracture Registry. Online dashboard. https:// sampo.thl.fi/pivot/prod/fi/perfect/lmtuotpts/summary_table? mittari_0 $=96182 \&$ mittari_0 $=135316 \&$ mittari_0 $=96223 \&$ mittari_0 $=96210 \&$ mittari_ $0=96211 \&$ mittari_ $0=96219 \& \mathrm{mitta}$ ri_0 $=135002 \&$ mittari_0 $=134996 \&$ mittari_0 $=141085 \&$ mitta ri_0 $=141083 \&$ mittari_0 $=141084 \&$ mittari_ $0=96220 \&$ mitta ri_0 $=96218 \&$ mittari_0 $=96192 \&$ mittari_0 $=96196 \&$ mittari_ $0=$ $96207 \&$ mittari_0 $=96189 \&$ mittari $0=96183 \&$ mittari $0=96186$ \&mittari_0 $=96213 \&$ mittari_0=96221\&aikamulti_0 $=131798 \&$ aikamulti_0 $=131829 \&$ aikamulti_0 $=131818 \&$ aikamulti_0 $=$ $131847 \&$ aikamulti_0 $=131841 \&$ aikamulti_0 $=131822 \&$ aikam ulti_0 $=131839 \&$ aikamulti_0 $=131846 \&$ aikamulti_0 $=13182$ 6\&aikamulti_0=131832\&aikamulti_0=131833\&aikamulti_0= 131834\&aikamulti_0 $=131864$ \&aikamulti_ $0=131811 \&$ aikam ulti_0=131856\&aikamulti_0=131819\&aikamulti_0=224556\& aikamulti_0=323814\&aikamulti_0=424912\#. (Accessed 9 June 2021)

28. Ferrara MC, Andreano A, Tassistro E, Rapazzini P, Zurlo A, Volpato S, Mussi C, Corsi M, Lunardelli ML, Martini E, Castoldi G, De Filippi F, Pizzonia M, Monacelli F, Barone A, Pilotto A, March A, Ungar A, Capelli R, Galmarini V, Franzoni S, Terragnoli F, Bianchetti A, Cazzulani I, Gandossi C, Valsecchi MG, Bellelli G; GIOG study group. Three-year national report from the Gruppo Italiano di Ortogeriatria (GIOG) in the management of hip-fractured patients. Aging Clin Exp Res. 2020;32(7):1245-53.

29. Zurlo A, Bellelli G. Orthogeriatrics in Italy: the Gruppo Italiano di Orthogeriatria (GIOC) audit on hip fractures in the elderly. Geriatric Care. 2018;4:7726.

30. Kristensen PK, Röck ND, Christensen HC, Pedersen AB. The Danish multidisciplinary hip fracture registry 13 -year results from a population-based cohort of hip fracture patients. Clin Epidemiol. 2020;12:9-21.

31. Sund R, Juntunen M, Lüthje P, Huusko T, Häkkinen U. Monitoring the performance of hip fracture treatment in Finland. Ann Med. 2011;43(Suppl 1):S39-46.

32. Voeten SC, Arends AJ, Wouters MWJM, Blom BJ, Heetveld MJ, Slee-Valentijn MS, Krijnen P, Schipper IB, Hegeman JHH; Dutch Hip Fracture Audit (DHFA) Group. The Dutch hip fracture audit: evaluation of the quality of multidisciplinary hip fracture care in the Netherlands. Arch Osteoporos. 2019;14(1):28.

33. Hughes AJ, Hennessy O, Brennan L, Rana A, Murphy CG. How accurate is the data provided to the Irish Hip Fracture Database? Ir J Med Sci. 2019;188(1):13-8.

34. Hjelholt TJ, Edwards NM, Vesterager JD, Kristensen PK, Pedersen $\mathrm{AB}$. The positive predictive value of hip fracture diagnoses and surgical procedure codes in the Danish multidisciplinary hip fracture registry and the Danish national patient registry. Clin Epidemiol. 2020;12:123-31.

35. Lawrence JE, Cundall-Curry D, Stewart ME, Fountain DM, Gooding CR. The use of an electronic health record system reduces errors in the National Hip Fracture Database. Age Ageing. 2019;48(2):285-90.

36. Cundall-Curry DJ, Lawrence JE, Fountain DM, Gooding CR. Data errors in the National hip fracture database: a local validation study. Bone Joint J. 2016;98-B(10):1406-9.

37. Voeten SC, van Bodegom-Vos L, Hegeman JH, Wouters MWJM, Krijnen P, Schipper IB. Hospital staff participation in a national hip fracture audit: facilitators and barriers. Arch Osteoporos. 2019;14(1):110.

38. Diagnosedaten der Krankenhäuser ab 2000 (Eckdaten der vollstationären Patienten und Patientinnen). Gliederungsmerkmale: Jahre, Behandlungs-/Wohnort, ICD-10 (Primärquelle: Statistisches Bundesamt, Krankenhausstatistik-Diagnosedaten der Patienten und Patientinnen in Krankenhäusern). In www.gbebund.de (Thematische Recherche: Startseite > Krankheiten/ Gesundheitsprobleme > Skelett, Muskeln, Bindegewebe-Frakturen $>$ Tabelle (gestaltbar): Diagnosedaten der Krankenhäuser (Eckdaten der vollstationären Patienten und Patientinnen)). (Accessed 19 June 2021)

39. Jiménez-Mola S, Calvo-Lobo C, Idoate-Gil J, Seco-Calvo J. Functionality, comorbidity, complication \& surgery of hip fracture in older adults by age distribution. Rev Assoc Med Bras (1992). 2018;64(5):420-7.

40. Voeten SC, Nijmeijer WS, Vermeer M, Schipper IB, Hegeman JH; DHFA Taskforce study group. Validation of the fracture mobility score against the parker mobility score in hip fracture patients. Injury. 2020;51(2):395-9.

41. Fox KM, Magaziner J, Hebel JR, Kenzora JE, Kashner TM. Intertrochanteric versus femoral neck hip fractures: differential characteristics, treatment, and sequelae. J Gerontol A Biol Sci Med Sci. 1999;54(12):M635-40.

42. Muhm M, Amann M, Hofmann A, Ruffing T. Veränderung der patientenklientel mit hüftgelenknahen femurfrakturen in der letzten dekade: Inzidenz, Alter, Nebenerkrankungen und Liegezeiten [Changes in the patient population with proximal femur fractures over the last decade: incidence, age, comorbidities, and length of stay]. Unfallchirurg. 2018;121(8):649-56.

43. Butt FF, Hussain AS, Khan AM, Sultan M. Implants for extracapsular neck of femur fracture dynamic hip screw versus intramedullary nailing. J Ayub Med Coll Abbottabad. 2017;29(4):697-701.

44. Zhang K, Zhang S, Yang J, Dong W, Wang S, Cheng Y, AlQwbani M, Wang Q, Yu B. Proximal femoral nail vs dynamic hip screw in treatment of intertrochanteric fractures: a meta-analysis. Med Sci Monit. 2014;20:1628-33.

45. Sharma A, Sethi A, Sharma S. Treatment of stable intertrochanteric fractures of the femur with proximal femoral nail versus dynamic hip screw: a comparative study. Rev Bras Ortop. 2017;53(4):477-81.

46. Ma HH, Chou TA, Tsai SW, Chen CF, Wu PK, Chen WM. Outcomes of internal fixation versus hemiarthroplasty for elderly patients with an undisplaced femoral neck fracture: a systematic review and meta-analysis. J Orthop Surg Res. 2019;14(1):320.

47. Kristensen TB, Dybvik E, Kristoffersen M, Dale H, Engesæter LB, Furnes O, Gjertsen JE. Cemented or uncemented hemiarthroplasty 
for femoral neck fracture? Data from the Norwegian hip fracture register. Clin Orthop Relat Res. 2020;478(1):90-100.

48. Fenelon C, Murphy EP, Pomeroy E, Murphy RP, Curtin W, Murphy CG. Perioperative mortality after cemented or uncemented hemiarthroplasty for displaced femoral neck fractures-a systematic review and meta-analysis. J Arthroplasty. 2021;36(2):777-787.e1.

49. White SM, Moppett IK, Griffiths R. Outcome by mode of anaesthesia for hip fracture surgery. An observational audit of 65535 patients in a national dataset. Anaesthesia. 2014;69(3):224-30.

50. Ilango S, Pulle RC, Bell J, Kuys SS. General versus spinal anaesthesia and postoperative delirium in an orthogeriatric population. Australas J Ageing. 2016;35(1):42-7.

51. Guay J, Parker MJ, Gajendragadkar PR, Kopp S. Anaesthesia for hip fracture surgery in adults. Cochrane Database Syst Rev. 2016;2(2):CD000521

52. Kowark A, Adam C, Ahrens J, Bajbouj M, Bollheimer C, Borowski M, Dodel R, Dolch M, Hachenberg T, Henzler D, Hildebrand F, Hilgers RD, Hoeft A, Isfort S, Kienbaum P, Knobe M, Knuefermann P, Kranke P, Laufenberg-Feldmann R, Nau C, Neuman MD, Olotu C, Rex C, Rossaint R, Sanders RD, Schmidt R, Schneider F, Siebert H, Skorning M, Spies C, Vicent O, Wappler F, Wirtz DC, Wittmann M, Zacharowski K, Zarbock A, Coburn M; iHOPE study group. Improve hip fracture outcome in the elderly patient (iHOPE): a study protocol for a pragmatic, multicentre randomised controlled trial to test the efficacy of spinal versus general anaesthesia. BMJ Open. 2018;8(10):e023609.

53. British Orthopaedic Association and British Geriatric Society. The Blue Book. (2007). https://www.bgs.org.uk/sites/default/files/ content/attachment/2018-05-02/Blue\%20Book\%20on\%20fragility\%20fracture\%20care.pdf. (Accessed 19 June 2021)

54. Grimes JP, Gregory PM, Noveck H, Butler MS, Carson JL. The effects of time-to-surgery on mortality and morbidity in patients following hip fracture. Am J Med. 2002;112(9):702-9.

55. Vidán MT, Sánchez E, Gracia Y, Marañón E, Vaquero J, Serra JA. Causes and effects of surgical delay in patients with hip fracture: a cohort study. Ann Intern Med. 2011;155(4):226-33.

56. Schoeneberg C, Aigner R, Pass B, Volland R, Eschbach D, Peiris SE, Ruchholtz S, Lendemans S, AltersTraumaRegister DGU. Effect of time-to-surgery on in-house mortality during orthogeriatric treatment following hip fracture: a retrospective analysis of prospectively collected data from 16,236 patients of the AltersTraumaRegister DGUß. Injury. 2021;52(3):554-61.

57. Moyet J, Deschasse G, Marquant B, Mertl P, Bloch F. Which is the optimal orthogeriatric care model to prevent mortality of elderly subjects post hip fractures? A systematic review and meta-analysis based on current clinical practice. Int Orthop. 2019;43(6):1449-54.

58. Grigoryan KV, Javedan H, Rudolph JL. Orthogeriatric care models and outcomes in hip fracture patients: a systematic review and meta-analysis. J Orthop Trauma. 2014;28(3):e49-55.

59. Werner M, Krause O, Macke C, Herold L, Ranker A, Krettek C, Liodakis E. Orthogeriatric co-management for proximal femoral fractures. Can two additions make a big difference? BMC Musculoskelet Disord. 2020;21(1):371.

60. Wagner P, Fuentes P, Diaz A, Martinez F, Amenabar P, Schweitzer D, Botello E, Gac H. Comparison of complications and length of hospital stay between orthopedic and orthogeriatric treatment in elderly patients with a hip fracture. Geriatr Orthop Surg Rehabil. 2012;3(2):55-8.

61. Rizk P, Morris W, Oladeji P, Huo M. Review of postoperative delirium in geriatric patients undergoing hip surgery. Geriatr Orthop Surg Rehabil. 2016;7(2):100-5.

62. Jennnison T, Yarlagadda R. A case-control study of 30-day mortality in periprosthetic hip fractures and hip fractures. Ann R Coll Surg Engl. 2020;102(3):229-31.

63. Currie C. Hip fracture audit: creating a "critical mass of expertise and enthusiasm for hip fracture care"? Injury. 2018;49(8):1418-23.

64. Leal J, Gray AM, Prieto-Alhambra D, Arden NK, Cooper C, Javaid MK, Judge A; REFReSH study group. Impact of hip fracture on hospital care costs: a population-based study. Osteoporos Int. 2016;27(2):549-58.

65. Neuburger J, Currie C, Wakeman R, Tsang C, Plant F, De Stavola B, Cromwell DA, van der Meulen J. The impact of a national clinician-led audit initiative on care and mortality after hip fracture in England: an external evaluation using time trends in non-audit data. Med Care. 2015;53(8):686-91.

66. Gjertsen JE, Dybvik E, Furnes O, Fevang JM, Havelin LI, Matre K, Engesæter LB. Improved outcome after hip fracture surgery in Norway. Acta Orthop. 2017;88(5):505-11.

67. Edwards GA, Metcalfe AJ, Johansen A, O'Doherty D. Performance monitoring in hip fracture surgery-how big a database do we really need? Injury. 2010;41(4):374-6.

68. Slobogean GP, Giannoudis PV, Frihagen F, Forte ML, Morshed S, Bhandari M. Bigger data, bigger problems. J Orthop Trauma. 2015;29(Suppl 12):S43-6. 